\title{
A CONSTRUÇÃO DE UMA HERMENÊUTICA JURÍDICA AMBIENTAL COMO EXPRESSÃO DO ESTADO SOCIOAMBIENTAL DE DIREITO
}

\author{
THE CONSTRUCTION OF AN ENVIRONMENTAL LEGAL HERMENEUTICS AS \\ AN EXPRESSION OF THE SOCIO-ENVIRONMENTAL STATE OF LAW
}

\author{
André Luiz Staack ${ }^{1}$ \\ Célia Regina Capeleti ${ }^{2}$
}

\section{RESUMO}

Este artigo objetivou identificar possíveis métodos, técnicas e meios próprios de interpretação que traduzam os anseios do Estado Socioambiental de Direito e auxiliem na solução dos atuais conflitos sociais. Para o alcance do objetivo proposto, o método de abordagem foi o indutivo, sendo o levantamento de dados realizado através da técnica da pesquisa bibliográfica de fonte secundária. Nas considerações finais, concluiu-se que a construção de uma hermenêutica jurídica ambiental e do Estado Socioambiental de Direito deve restar balizada numa visão ontológica da sustentabilidade, abarcando todas as suas dimensões, bem como na formação de uma pré-compreensão geral e específica do intérprete.

Palavras-chave: Estado Liberal. Estado Social. Estado Socioambiental de Direito. Hermenêutica Jurídica Ambiental.

\begin{abstract}
This article aimed to identify possible methods, techniques and means of interpretation that reflect the aspirations of the Socio-environmental State of Law and assist in the solution of current social conflicts. To reach the objective, the method was the inductive, and the data collection carried out through the technique of the bibliographic research of secondary source. In conclusion, it was considerated that the construction of an environmental legal hermeneutics and the Socio-environmental State of Law must be based on an ontological vision of sustainability, encompassing all dimensions, as well as in the formation of a general and specific pre-comprehension of the interpreter.
\end{abstract}

Keywords: Liberal State. Welfare State. Socio-environmental State of Law. Environmental Legal Hermeneutics.

\footnotetext{
${ }^{1}$ Mestrando em Ciência Jurídica pela Universidade do Vale do Itajaí - UNIVALI - Santa Catarina (Brasil). Oficial de Justiça e Avaliador do Poder Judiciário de Santa Catarina. E-mail: staack@tjsc.jus.br

${ }^{2}$ Mestranda em Ciência Jurídica pela Universidade do Vale do Itajaí - UNIVALI - Santa Catarina (Brasil). Técnica Judiciária do Poder Judiciário de Santa Catarina. E-mail: celia.capeleti@tjsc.jus.br
} 


\section{INTRODUÇÃO}

O presente trabalho tem por objetivo identificar possíveis métodos, técnicas e meios próprios de interpretação que traduzam os anseios do Estado Socioambiental de Direito e, concomitantemente, auxilie na solução dos atuais conflitos sociais.

Na delimitação do tema, levantou-se o seguinte problema: há como se cogitar de métodos, técnicas e meios próprios de interpretação que, de fato, sirvam de base para uma firme edificação do Estado Socioambiental de Direito e, simultaneamente, auxiliem na solução dos conflitos sociais hodiernos?

Para o equacionamento do problema partiu-se da seguinte hipótese: considerando a estruturação do Estado Socioambiental de Direito e de sua base solidária de construção social, há como se cogitar de métodos, técnicas e meios próprios de interpretação. Para tanto, há que se edificar uma proposta hermenêutica que traduza os anseios do paradigma estatal em formação, bem como seja efetiva na solução dos conflitos sociais atuais.

Para seu desenvolvimento, inicialmente, estudar-se-á a formação do Estado Moderno, dando-se ênfase aos modelos do Estado Liberal e do Estado Social, conjugando-os com a teoria dos direitos fundamentais. Em seguida, abordar-se-á o Estado de Direito Ambiental, sua composição teórica e seus pilares estruturantes. Por fim, analisar-se-á uma possível proposta hermenêutica jurídica ambiental que exprima os anseios do Estado Socioambiental de Direito e que, assim, conduza a uma solução os conflitos sociais atuais.

O critério metodológico utilizado para essa investigação e a base lógica do relato dos resultados apresentados reside no Método Indutivo (PASOLD, 2015, p. 90-93; 97-99). Na fase de Tratamento dos Dados, utilizou-se o Método Cartesiano (PASOLD, 2015, p. 92).

As técnicas utilizadas nesse estudo serão a Pesquisa Bibliográfica, a Categoria e o Conceito Operacional, quando necessário (PASOLD, 2015, p. 93-97; 108; 113-130). Outros instrumentos de Pesquisa, além daqueles anteriormente mencionados, poderão ser acionados para que o aspecto formal desse estudo se torne esclarecedor ao leitor.

\section{DA FORMAÇÃO DO ESTADO MODERNO AO ESTADO SOCIAL}

Durante a Idade Média vigorava o sistema feudal, politicamente descentralizado, escorado nas antigas tradições germânicas do comitatum que se traduzia nas simbióticas relações de suserania e vassalagem. Tal sistema operou por quase mil anos de maneira 
heterogênea na Europa, variando regional e temporalmente. Nesse contexto, a concepção de Estado, enquanto instituição materialmente concentradora da coerção, apta a estampar a unidade de um sistema de plenitude normativa e eficácia absoluta, estava arrefecida (BONAVIDES, 2010, p. 34).

Contudo, o Estado foi ganhando novos contornos com a passagem da Idade Média para a Idade Moderna, a qual foi marcada por uma transformação político-social onde os principais atores foram a classe aristocrática ${ }^{3}$ já estabelecida e a ascendente classe burguesa ${ }^{4}$ que crescia em riqueza e influência.

"Foi a soberania, por sem dúvida, o grande princípio que inaugurou o Estado Moderno" (BONAVIDES, 2010, p. 35), o qual tinha como principal característica a concentração de poderes na figura do rei, de modo que o Estado encontrava-se confuso com a figura do rei, o que pode ser observado na polêmica frase "O Estado sou eu", de Luís XIV da França. Isso significava que o rei estava acima da própria lei, sendo ela fruto de sua vontade.

Esta não era uma situação meramente alegórica, visto que teóricos do "Direito Divino dos Reis" reforçavam esse conceito e legitimavam a autoridade dos reis com o apoio da Igreja Católica, outro indissociável ator político do período. ${ }^{5}$

Com o passar do tempo, o crescimento econômico da burguesia e a evolução do pensamento político convergiram para um ponto de questionamento sobre as vantagens do sistema centralizador, que já não acomodava os novos interesses dessa classe. Várias revoluções liberais ocorrem em diversas partes da Europa (Puritana e Gloriosa na Inglaterra, Revolução Francesa na França por exemplo), acompanhadas de um ideário próprio da classe

\footnotetext{
${ }^{3}$ A aristocracia pressionada pelas constantes rebeliões de camponeses e em meio a intrincadas relações de alianças e guerras entre microrregiões próximas via a necessidade de uma autoridade centralizada forte que pudesse apaziguar os conflitos internos de cada reino e reagir de maneira mais organizada às ameaças externas. Mesmo que a passagem de um regime descentralizado para um centralizado representasse, superficialmente, a perda de poder político da aristocracia, esta manteria os seus privilégios de classe por apoiar a ascensão do rei.

4 A burguesia esperava dessa transformação a consolidação de padrões monetários, acordos alfandegários, planos de expansão, segurança nas rotas comerciais, enfim, medidas legais que lhe assegurasse a prática mercantil de maneira mais próspera. Para o reino, já unificado, tal situação permitiu a manutenção do status quo, na adequação a uma nova realidade político-social sem, no entanto, prejudicar as classes dominantes.

5 Deste contexto destacam-se os seguintes autores e suas obras: MAQUIAVEL, Nicolau (Niccolò di Bernardo dei Machiavelli). O Príncipe. Tradução de Pietro Nassetti. São Paulo: Editora Martin Claret. Título original: il Principe (15131516), na qual o autor apresenta um manual para a manutenção e crescimento do poder do monarca. HOBBES, Thomas. Leviatã ou Matéria, Forma e Poder de um Estado Eclesiático e Civil. Tradução de Alex Martins. São Paulo: Editora Martin Claret. Título original: Leviathan, ou Matter, Form and Power of a Commenweath Ecclesiastical and Civil. 2002, na qual o autor defende o fortalecimento do poder absoluto, uma vez que homem, por estar numa condição constante de guerra, precisa ser submetido a este poder a fim de obter a paz. BODIN. Jean. Os Seis Livros da República. Tradução de José Ignácio Coelho Mendes. São Paulo: Saraiva. Título Original: Les six livres de la République (1576), na qual o autor defende que o poder soberano do monarca é reflexo do poder divino e, portanto, os súditos a ele devem obediência; BOSSUET. Jacques. Política Tirada das Santas Escrituras (1708). Título Original: Politique Tirée des propres paroles de Lécreiture Saint, na qual o autor sustenta que os reis recebiam seus poderes de Deus e, portanto, o governo era divino.
} 
burguesa e contra os privilégios da aristocracia, em busca da democracia e da justiça. Assim, com a queda da Bastilha caiu a velha roupagem do Estado que, a partir de então, ganhou novos contornos, passando de Estado absoluto para Estado constitucional.

No Estado Constitucional "[...] o poder já não é das pessoas, mas de leis. São leis, e não personalidades, que governam o ordenamento social e político. A legalidade é a máxima de valor supremo e se traduz com toda energia no texto dos Códigos e das Constituições." (BONAVIDES, 2010, p. 43). Esse Estado é sustentado basicamente pela teoria do poder constituinte, pela separação dos poderes e pela democracia representativa.

Sendo o Estado Constitucional Moderno "[...] gênero do qual o Estado Liberal, Estado Social, Estado de Bem-Estar, Estado Contemporâneo e todas as outras denominações dadas às variações de seu âmbito de atuação são espécies" (CRUZ, 2011, p. 34), nos ateremos a estudar as características do Estado Liberal e do Estado Social, que inicialmente traduzem os ideários da liberdade e da igualdade da Revolução Francesa.

A primeira era do Estado Constitucional é marcada pelo liberalismo. Assim, o Estado Liberal é marcado profundamente pelos ideais da liberdade, que buscam fixar uma esfera de autonomia individual, traduzindo-se na abstenção dos governantes, criando obrigações de não fazer, de não intervir sobre aspectos da vida pessoal (MENDES; BRANCO, 2013, p. 137).

A liberdade, enquanto direito de primeira dimensão, marca profundamente o século XIX, o qual é tido como o século do Estado Liberal e das constituições liberais, (BONAVIDES, 2010, p. 47) uma vez que nesse século as declarações de direitos e constituições trouxeram em seu bojo grande camada de direitos fundamentais individuais, políticos e civis, uma vez que até então o povo se encontrava oprimido politicamente pelo poder absolutista.

Contudo, com o desenvolvimento industrial e a formação de uma classe operária, passou-se a verificar que somente as liberdades individuais não eram suficientes frente ao poder econômico, pois "[...] de nada adiantava as constituições e leis reconhecerem liberdades a todos, se a maioria não dispunha [...] de condições materiais para exercê-las" (SILVA, 2005, p. 159).

Nesse contexto, os ideais de igualdade, que se traduzem em direitos sociais e de justiça social, começam a ganhar mais espaço, porque "a liberdade já se tinha adquirida e positivada nos ordenamentos constitucionais, ao passo que a justiça, como anseio e valor social superior, estava ainda longe de alcançar o mesmo grau de inserção, positividade e concreção" (BONAVIDES, 2010, p. 48). 
Diante disso, ainda no século XIX, quando o Estado Liberal está em seu auge, começa a surgir o Estado Social ${ }^{6}$ e os direitos de segunda dimensão, ou seja, os direitos que, em regra ${ }^{7}$, demandam uma prestação positiva do Estado, começam a ganhar espaço nas constituições. $^{8}$ Em 1948 a Assembleia Geral das Nações Unidas adotou e proclamou a Declaração Universal dos Direitos Humanos, na qual apontou como ideal comum a ser atingido por todos os povos e nações inúmeros Direitos Sociais. ${ }^{9}$

Esse Estado Social, também chamado por Paulo Márcio Cruz de Estado Contemporâneo, Estado de Bem-Estar ou Estado Social Democrata, (CRUZ, 2003, p. 152) por meio da efetivação de direitos sociais e da intervenção direta na sociedade, busca "[...] garantir oportunidades iguais a seus cidadãos nos âmbitos econômico, social e cultural" (CRUZ, 2003, p. 153).

Contudo, embora ainda não efetivadas completamente "[...] as promessas da modernidade" (STRECK, 2014, p. 29), ou seja, os direitos de liberdade e igualdade, verificase que o Estado Constitucional Moderno e suas teorias fundamentais já não atendem eficazmente os novos desafios e necessidades da atual sociedade de risco. ${ }^{10}$ Vivemos na era da globalização e da tecnologia, marcada pelo multiculturalismo global, por profundas desigualdades sociais, por mudanças climáticas, por desastres ambientais, por escassez de recursos naturais, pela poluição, dentre outros inúmeros problemas que nem o Estado Liberal, nem o Estado Social puderam resolver, seja porque não estava entre seus objetivos, seja porque sucumbiram diante do poder econômico.

Fato é que na busca por cada vez mais direitos, os seres humanos e as formas de governo que foram estabelecendo, pouco se preocuparam com a proteção e conservação do

\footnotetext{
${ }^{6}$ Segundo Paulo Bonavides, as duas colunas de sustentação teórica do Estado Social foram levantadas durante o Século XX, pelos pensadores do Socialismo Utópico e do Socialismo Científico. in BONAVIDES. Paulo. Teoria Geral do Estado. p. 49. Ainda sobre o Estado Social: BONAVIDES, Paulo. Teoria Constitucional da Democracia Participativa. Por um Direito Constitucional de luta e resistência. Por uma Nova Hermenêutica. Por uma repolitização da legitimidade. 1 ed. São Paulo: Malheiros, 2001. p. 143 e ss.

${ }^{7}$ Falamos em regra, por ser esta uma característica que predomina nos direitos sociais, porém insta salientar que tais direitos também podem apresentar um componente negativo, conforme leciona Canotilho: "[...] o direito do trabalho não consiste apenas na obrigação do Estado de criar ou de contribuir para criar postos de trabalho [...], antes implica também a obrigação de o Estado de se abster de impedir ou limitar o acesso dos cidadãos ao trabalho (liberdade de acesso ao trabalho); o direito à saúde não impõe ao Estado apenas o dever de atuar para constituir o Serviço Nacional de Saúde e realizar as prestações de saúde [...], antes impõe igualmente que se abstenha de atuar de modo a prejudicar a saúde dos cidadãos." in CANOTILHO. José Joaquim Gomes; MOREIRA, Vital. Fundamentos da Constituição. Coimbra: Coimbra, 1991. p. 127.

${ }^{8}$ A Constituição Mexicana de 1917 foi a primeira A sistematizar um conjunto de Direitos Sociais do Homem, seguida pela Constituição de Weimar de de 1919. No Brasil, a primeira Constituição a tratar dos Direitos Sociais foi a de 1934. Atualmente a Constituição de 1988 tem amplo rol de direitos sociais em seu texto, especialmente em seu artigo $6^{\circ}$.

${ }^{9}$ Especialmente a partir de seu artigo 23.

10 Segundo Ulrick Beck, a sociedade de risco é aquela submetida a fortes riscos e processos de individualização, marcada por catástrofes ecológicas, crises financeiras, terrorismo e guerra. in Sociedade de Risco. Rumo a Outra Modernidade. 2 ed. São Paulo: Editora 34, 2011.
} 
planeta e das demais formas de vida que nele coexistem, de modo que é chegado o momento do ideário da fraternidade ser o balizar do modelo de Estado. Fraternidade entre os seres humanos. Fraternidade entre os seres vivos. Sobre isso, discorreremos a seguir.

\section{OS PILARES DO ESTADO SOCIOAMBIENTAL DE DIREITO}

O Estado Socioambiental de Direito, também denominado pela doutrina, nas palavras de Tiago Fensterseifer (2008, p. 94), como Estado Pós-Social, Estado Constitucional Ecológico, Estado de Direito Ambiental, Estado do Ambiente, Estado Ambiental de Direito, Estado de Bem-Estar Ambiental, dentre outros, “[...] valendo-se de seus atributos jurídicos e institucionais, tem o objetivo de fornecer a mínima segurança necessária para a garantia da qualidade de vida sob o enfoque ambiental" (ARMADA, 2015, p. 162).

José Joaquim Gomes Canotilho, utilizando-se da expressão Estado Constitucional Ecológico, resume o modelo estatal em estudo nos seguintes enunciados:

(1) o Estado constitucional, além de ser e dever ser um Estado de Direito democrático e social, deve ser também um Estado regido por princípios ecológicos; (2) o Estado ecológico aponta para formas novas de participação política sugestivamente condensadas na expressão democracia sustentada. (2001, p. 9)

Para autor, ademais, “[...] um Estado constitucional ecológico pressupõe uma concepção integrada ou integrativa do ambiente e, consequentemente, um direito integrado e integrativo do ambiente" (CANOTILHO, 2001, p. 12), ou seja, para ele o Estado deve ter por fim amparar para além do meio ambiente natural, salvaguardando, assim, uma relação direta dos bens naturais com o todo que o cerca. É mais do que defender uma árvore, um habitat ou uma espécie, é resgatar a vida e proteger, hodiernamente, cada partícula de nosso planeta.

Tal concepção integrativa pressupõe, destarte, uma avaliação ambiental que não recai apenas sobre projetos públicos ou privados isolados, mas sim atinge políticas, planos e programas estatais de ampla abrangência social que, numa análise e construção prévias, servirá de base para criação de regras de caracteres variados. ${ }^{11}$

Nesse rumo, a avaliação ambiental estratégica, instrumento ainda em construção no Brasil, é um claro exemplo dessa concepção integrativa do ambiente, pois é concebida “[...] como [...] de cognição prévio, participativo, holístico, integral e sistemático que qualifica e densifica, na perspectiva material, as escolhas públicas com ampla repercussão na qualidade de vida humana e no ecossistema" (BODNAR; ROSSETTO; BODNAR, 2015, p. 54). Tal

\footnotetext{
11 “[...] a concepção integrativa pressuporá uma avaliação integrada de impacto ambiental incidente não apenas sobre projectos públicos ou privados isoladamente considerados, mas sobre os próprios planos (planos directores municipais, planos de urbanização). Isto implica uma notável alteração das relações entre as dimensões ambientais e as dimensões urbanísticas." In: CANOTILHO, José Joaquim Gomes - Estado constitucional e democracia sustentada. p. 12.
} 
instrumento, portanto, é expressão do Estado Socioambiental de Direito, devendo ser incorporado e efetivado o quanto antes possível no ordenamento jurídico interno.

Quanto ao papel do Estado Socioambiental de Direito no atual panorama de proteção dos direitos fundamentais, Tiago Fensterseifer aduz:

[...] A fim de reparar o débito social do projeto burguês do Estado Liberal e agregar a dimensão coletiva da condição humana alçada pelo Estado Social, projeta-se, hoje, no horizonte jurídico da comunidade estatal o modelo de Estado Socioambiental, que, conjugando as conquistas positivas (em termos de tutela da dignidade humana) dos modelos de Estado de Direito que antecederam, possa incorporar a tutela dos novos direitos transindividuais e, num paradigma de solidariedade humana (nas dimensões nacional, supranacional e mesmo intergeracional), projetar a comunidade humana num patamar mais evoluído de efetivação de direitos fundamentais (especialmente dos novos direitos de terceira dimensão) e de concretização de uma vida humana digna e saudável a todos os seus membros (2008, p. 97).

Sendo assim, busca-se com tal modelo estatal proporcionar aos seres viventes as condições mínimas para além da mera sobrevivência, bem como, tendo por base a proteção eficiente do ambiente, efetivar direitos já consagrados nos modelos estatais anteriores direitos fundamentais de primeira e segunda gerações - em comunhão com os então estabelecidos direitos difusos.

O direito ao meio ambiente equilibrado, neste diapasão, é tratado como um direito difuso, tendo em vista que se trata, nos moldes do art. 81, parágrafo único, inciso I, do Código de Defesa do Consumidor, de um direito transindividual, de natureza indivisível, de que são titulares pessoas indeterminadas e ligadas por circunstâncias de fato (BRASIL, 1990).

Norberto Bobbio, tratando do tema, assim consigna:

Ao lado dos direitos sociais, que foram chamados de direitos de segunda geração, emergiram hoje os chamados direitos de terceira geração, que constituem uma categoria para dizer a verdade, ainda excessivamente heterogênea e vaga, o que nos impede de compreender do que efetivamente se trata. $\mathrm{O}$ mais importante deles é o reivindicado pelos movimentos ecológicos: o direito de viver num ambiente não poluído (1992, p. 6).

Ademais, os direitos difusos - direitos fundamentais de terceira geração - são também conhecidos como direitos de solidariedade, pois encampam uma concepção de titularidade universal, comunitária e transpessoal. Nesses moldes, Jeferson Dytz Marin e Pavlova Perizzollo Leonardelli registram:

[...] os direitos de terceira dimensão ou também denominados "novos direitos", possuem caráter difuso e coletivo, sendo a coletividade o titular desses direitos, podendo expressar-se através das mais diversas categorias de pessoas ou de um grupo de pessoas, tendo em vista que o meio ambiente é considerado como um bem de toda a sociedade (2013, p. 374-386)

Portanto, o meio ambiente deve ser considerado, como acima exposto, bem de toda a sociedade, razão pela qual necessita de proteção por parte dos agentes sociais, enquanto membros da atual sociedade de risco, em conjunto com a salvaguarda oferecida pelo Estado, com base nesse estudo, pelo Estado Socioambiental de Direito. 
Os riscos ${ }^{12}$ gerados pelas condutas irresponsáveis dos seres humanos no trato com os bens naturais, com os seus e com os seres não humanos deram ensejo à necessidade de se buscar, em especial em virtude do atual panorama da sociedade, um modelo de Estado que, efetivamente, comungue, em seus anseios, os ideais da tríade liberdade-igualdadefraternidade. Objetivando unificar tal lema, surgiu o Estado Socioambiental de Direito.

A liberdade, neste modelo estatal, vem estampada como uma articuladora de oportunidades e geradora de um mínimo existencial social ${ }^{13}$ e ecológico ${ }^{14}$, ou seja, está ligada, diretamente, à ideia de plena autonomia e igualdade de condições dos seres viventes. Nesse rumo, assinala Tiago Fensterseifer que "[...] sem o acesso a tais condições existenciais mínimas, não há que se falar em liberdade real ou fática, quanto menos em um padrão de vida compatível com a dignidade humana" (2008, p. 271).

O filósofo Immanuel Kant (1960, p. 78), em sua obra Fundamentação da metafísica dos costumes, explana que a "[...] Autonomia é pois o fundamento da dignidade da natureza humana e de toda a natureza racional." Só com autonomia e vontade livre, portanto, que o ser humano pode, de fato, ser considerado um ente verdadeiramente liberto de suas amarras.

Leonardo Boff, ao construir um conceito integrador de sustentabilidade,$^{15}$ defende, nos mesmos termos, a ideia de autonomia do ser humano como expressão da efetiva liberdade. Assim advoga:

[...] o sentido mais raso e realístico da sustentabilidade se realiza quando cada indivíduo puder viver autonomamente, ganhar seu pão, para ele e para sua família, conseguir chegar ao final do mês com as contas pagas, de alimentação, de água, de luz, de telefone, de internet, de aluguel

\footnotetext{
12 “[...] o risco é um conceito que tem sua origem na modernidade, dissociando-se de uma dimensão de justificação mítica e tradicional da realidade, relacionada com a verificação de contingências, eventos naturais e catástrofes, atribuídos a causas naturais e à intervenção divina, para se aproximar de uma dimensão que seleciona como objetos as consequências e os resultados de decisões humanas (justificadas, portanto, racionalmente), e que se encontram associadas ao processo civilizacional, à inovação tecnológica e ao desenvolvimento econômico gerados pela industrialização.” In LEITE, José Rubens Morato; AYALA, Patryck de Araújo. Direito ambiental na sociedade de risco. $2^{\mathrm{a}}$ ed. revista, atualizada e ampliada. Rio de Janeiro: Forense Universitária, 2004. p. 12-13.

${ }^{13}$ Mínimo existencial social: “[...] o conceito de mínimo existencial está diretamente relacionado à dimensão existencial humana mais elementar, conferindo a todo cidadão a garantia constitucional do acesso a um conjunto mínimo de prestações sociais, que pode tomar tanto a feição de um direito de natureza defensiva quando negativa, sem o qual a sua dignidade se encontraria profundamente comprometida ou mesmo sacrificada." In FENSTERSEIFER, Tiago. Direitos fundamentais e proteção do ambiente: a dimensão ecológica da dignidade humana no marco jurídico constitucional do Estado Socioambiental de Direito. p. 265.

${ }^{14}$ Mínimo existencial ecológico: “[...] a vinculação entre os direitos fundamentais sociais e o direito fundamental ao ambiente joga um papel central na composição de um quadro da condição humana que garanta uma existência digna, servindo, portanto, de fundamento normativo para a configuração da garantia constitucional aqui designada de mínimo existencial ecológico (ou socioambiental)." In FENSTERSEIFER, Tiago. Direitos fundamentais e proteção do ambiente: a dimensão ecológica da dignidade humana no marco jurídico constitucional do Estado Socioambiental de Direito, p. 271.

15 Conceito integrador de sustentabilidade: "Sustentabilidade é toda ação destinada a manter as condições energéticas, informacionais, físico-químicas que sustentam todos os seres, especialmente a Terra viva, a comunidade de vida, a sociedade e a vida humana, visando sua continuidade e ainda atender as necessidades da geração presente e das futuras, de tal forma que os bens e serviços naturais sejam mantidos e enriquecidos em sua capacidade de regeneração, reprodução $e$ coevolução.” In BOFF, Leonardo. Sustentabilidade: o que é, o que não é. 3. ed. Petrópolis: Editora Vozes, 2014. p. 107.
} 
da casa, de transporte, de educação e de outras coisas básicas da infraestrutura material (2014, p. 160).

Sendo assim, na concepção do Estado Socioambiental de Direito, a ideia de liberdade é revisitada, objetivando superar a concepção liberal individualista edificada no surgimento do Estado Moderno para, assim, proporcionar a todos os seres viventes, com igualdades de condições, uma concepção substancial de liberdade.

A igualdade, por sua vez, é mantida nos mesmos moldes construídos no anterior Estado Social, pregando, tão somente, a partir da edificação do Estado Socioambiental de Direito, um perfil modificado dos direitos prestacionais (maior efetivação dos direitos sociais). Rafael Luiz Ferronatto, Diogo Petry, Vinícius Borges Fortes e Raquel Fabiana Sparemberger tratam do tema nos seguintes termos:

Essa nova modalidade de Estado diz respeito a um perfil modificado dos direitos sociais, exigindo, ações de cidadania compartilhada entre Estado e cidadãos em busca da preservação ecológica, utilizando-se de mecanismos precaucionais, preventivos, tanto de responsabilização, como de preservação e reconstituição (2009, p. 01-22).

Ademais, a igualdade neste modelo estatal é tratada como condição necessária para a sadia qualidade de vida e para bom desenvolver do ser vivente, sendo edificada em consonância com o conceito kantiano de dignidade da pessoa humana.

Para Immanuel Kant, a concepção de dignidade humana, embora não retratada como tal expressão em sua obra, está atrelada ao seguinte imperativo categórico ${ }^{16}$ : “[...] Age de tal maneira que uses a humanidade, tanto na tua pessoa como na pessoa de qualquer outro, sempre e simultaneamente como fim e nunca simplesmente como meio" (KANT, 1960, p. 68). Desse modo, o autor aduz que o ser humano tem que usar a humanidade sempre como fim, e não como meio. Os atos praticados pelos seres humanos não podem considerar o outro como uma coisa, como meio, mas sim como um fim em si mesmo.

Tratando sobre o conceito kantiano de dignidade humana, Tiago Fensterseifer elucida:

A matriz filosófica moderna da concepção de dignidade humana está no pensamento do filósofo alemão Immanuel Kant. Até hoje a fórmula elaborada por Kant conduz a grande maioria das conceituações jurídico-constitucionais da dignidade humana, conforme se pode apreender da leitura do art. I da Declaração Universal dos Direitos Humanos (1948) referido acima. A formulação kantiana coloca a idéia de que o ser humano não pode ser empregado como simples meio (ou seja, objeto) para a satisfação de qualquer vontade alheia, mas sempre deve ser tomado como fim em si mesmo (ou seja, sujeito) em qualquer relação, seja em face do

16 “[...] só o imperativo categórico tem o carácter de uma lei prática, ao passo que todos os outros se podem chamar em verdade princípios da vontade, mas não leis; porque o que é somente necessário para alcançar qualquer fim pode ser considerado em si como contingente, e podemos a todo o tempo libertar-nos da prescrição renunciando à intenção, ao passo que o mandamento incondicional não deixa à vontade a liberdade de escolha relativamente ao contrário do que ordena, só ele tendo portanto em si aquela necessidade que exigimos na lei." In: KANT, Immanuel. Fundamentação da metafísica dos costumes. p. 54-55. Destaques no original. 
Estado seja em face de particulares. Isso se deve, em grande medida, pelo reconhecimento de um valor intrínseco a cada existência humana. A fórmula de se tomar sempre o ser humano como um fim em si mesmo está diretamente vinculada à idéia de autonomia, de liberdade, de racionalidade e de autodeterminação inerentes à condição humana. A proteção ética e jurídica do ser humano contra qualquer 'objetificação' da sua existência e o respeito à sua condição de sujeito nas relações sociais e intersubjetivas são manifestações da concepção kantiana de dignidade humana (2008, p. 31).

Entretanto, tal concepção tratada como referência para a edificação do Estado Socioambiental de Direito, embora relevante, é criticada pelo autor em sua obra, motivado pelo fato de que Kant, quando da construção de seu pensamento, só tratou da dignidade da pessoa humana, olvidando os demais seres viventes enquanto possuidores de tal condição existencial mínima. Vejamos:

Tanto o pensamento de Kant quanto todas as concepções que sustentam ser a dignidade atributo exclusivo da vida humana encontram-se, ao menos em tese, sujeitas à crítica de um excessivo antropocentrismo, notadamente naquilo em que sustentam, que a pessoa humana, em relação aos demais seres vivos (FENSTERSEIFER, 2008, p. 37).

Sem delongas, a igualdade no Estado Socioambiental de Direito, atrelada à ideia de dignidade humana, deve ser compreendida com base na concepção kantiana, mas, contudo, não merece prosperar tão somente atrelada ao ser humano, mas sim como fim de proteção de qualquer ser vivente.

Já a solidariedade é tratada como carro-chefe e um dos pilares do Estado Socioambiental de Direito, tendo em vista que ela traduz a essência de tal modelo político, qual seja, a de dar ênfase a ação conjunta entre Estado e Sociedade em prol de um bem comum. Deixa-se de lado o pensamento reducionista, mecanicista e individualista que por muito tempo construiu o pensamento social e científico para dar espaço a uma visão holística de vida (CAPRA, 2006).

Ademais, a participação popular é presença marcante no Estado Socioambiental de Direito, não somente como expressão do princípio da solidariedade, mas também como meio para resolução dos problemas originados com a sociedade de risco. A solidariedade toma o papel principal no modelo estatal em estudo, restando os agentes sociais como meros instrumentos para efetivação dos direitos fundamentais em todas suas dimensões.

No que concerne à participação popular e sua relevância no Estado Socioambiental de Direito, Javier Gonzaga Valencia Hernández explicita:

El estado ambiental genera espacios y mecanismos de deliberación pública para la construcción de consensos en materia ambiental, para involucrar de manera permanente en estos escenarios de participación pública a los actores populares y comunitarios, cuando se trate de tomar decisiones sobre el medio ambiente, lo que se presenta como una oportunidad para avanzar en la construcción de una democracia real (2007, p. 163-185).

Salienta-se, contudo, que a participação popular, no seio do Estado Socioambiental de Direito, não se encontra atrelada apenas no enfoque ambiental, mas sim tem vez em todas 
as áreas que tenham relevância para além da proteção do direito individual. Nesse contexto, o bem comum passa a substituir, em parte, o bem-estar individual, objetivando uma melhor interação do ser humano com o meio ambiente que o rodeia.

No que tange à forma de relação entre o homem e a natureza, constata-se que a visão antropocêntrica tradicional, “[...] que se caracteriza pela preocupação única e exclusiva com o bem estar do homem” (FERREIRA; LEITE, 2004, p. 28), não mais se sustenta na edificação de um Estado Socioambiental de Direito, devendo, para tanto, ser suprida, em uma, por uma visão ecológica profunda ou, em duas, por uma visão antropocêntrica alargada.

Fritjof Capra, em sua obra Teia da vida, contextualiza a percepção ecológica profunda assentando que "[...] A percepção ecológica profunda reconhece a interdependência fundamental de todos os fenômenos, e o fato de que, enquanto indivíduos e sociedades, estamos todos encaixados nos processos cíclicos da natureza (e, em última análise, somos dependentes desses processos)" (CAPRA. 2006, p. 25).

De tal modo, deixando de lado a percepção ecológica rasa, que remete à visão antropocêntrica tradicional, a percepção ecológica profunda passa a compreender a interdependência do ser humano com o meio ambiente que o rodeia como uma relação necessária para a preservação de nosso planeta. ${ }^{17}$ Tal percepção, portanto, como se percebe, pode ser considerada como um pilar do Estado Socioambiental de Direito, tendo em vista que se trata de uma visão holística e integradora.

Entretanto, Maria Leonor Paes Cavalcanti Ferreira e José Rubens Morato Leite defendem a ideia de que, embora a visão ecológica profunda tenha uma base axiológica firme, a visão adotada no ordenamento jurídico brasileiro é a do antropocentrismo alargado. Assim abordam o tema: "O Sistema Jurídico Brasileiro fundamentou-se no antropocentrismo alargado, sendo que, já na Constituição Federal de 1988, observa-se uma preocupação em preservar o meio ambiente como um todo" (FERREIRA; LEITE, 2004, p. 31).

Ademais, advogam os autores que a visão antropocêntrica alargada, além de reconstruir a relação do homem com a natureza, preocupa-se em garantir um meio ambiente ecologicamente equilibrado para as presentes e, mormente, futuras gerações (FERREIRA;

\footnotetext{
${ }^{17}$ A ecologia rasa é antropocêntrica ou centraliza no ser humano. Ela vê os seres humanos como situados acima ou fora da natureza, como fonte de todos os valores, e atribui apenas um valor instrumental, ou de 'uso' à natureza. A ecologia profunda não separa seres humanos - ou qualquer outra coisa - do meio ambiente natural. Ela vê o mundo não como uma coleção de objeto isolados, mas como uma rede de fenômenos que estão fundamentalmente interconectados e são interdependentes. A ecologia profunda reconhece o valor intrínseco de todos os seres vivos e concebe os seres humanos apenas como um fio particular na teia da vida. In CAPRA, Fritjof. Teia da vida. p. 25-26.
} 
LEITE, 2004, p. 30). Nasce, neste momento, mais um dos pilares do Estado Socioambiental de Direito, qual seja, o princípio da equidade intergeracional.

Consoante o princípio em tela, a proteção do meio ambiente e sua manutenção perene tem por fim garantir os bens naturais e que o circundam tanto para as presentes, quanto para as futuras gerações. Sobre o tema, versam Jeferson Dytz Marin e Pavlova Perizzollo Leonardelli:

[...] o princípio da equidade intergeracional decorre da efetivação do princípio da solidariedade. As relações do homem com o meio em que vive e a postura do Estado diante dos assuntos que tratam do ambiente constituem em uma condição que pode ou não assegurar um ambiente saudável e ecologicamente equilibrado para as gerações presentes e podem ou não garantir um legado ambiental às gerações futuras. A preservação do patrimônio ambiental depende do agir humano de forma consciente, responsável e consequentemente solidária (2013, p. 379).

O princípio da equidade intergeracional, portanto, é decorrência do princípio da solidariedade, tendo em vista que o que hoje é produzido com um espírito fraterno gerará efeitos tanto no presente quanto no futuro.

Por fim, há que se discorrer acerca do papel do agente social no Estado Socioambiental de Direito. Em tal modelo estatal, as condutas são realizadas prezando a proteção plena do meio ambiente e de tudo que o rodeia, bem como praticadas buscando agir de forma ética e altamente sustentável. Nesse contexto, advogam Jeferson Dytz Marin e Pavlova Perizzollo Leonardelli:

O ser humano precisa entender que o equilíbrio do ecossistema que habita é uma condição de existência de todos os seres do planeta. Também, precisa absorver seu dever em relação ao ambiente como algo que esteja intrínseco, que ocorra naturalmente e independa de preceito legal. Portanto, compete ao ser humano agir de forma ética, solidária e responsável perante o meio que habita, para que dessa forma possa cumprir com a sua tarefa na manutenção e preservação do meio ambiente para as presentes e futuras gerações (2013, p. 385).

Assim, a conscientização ambiental e o pensamento de base sustentável são partes integrantes do novo modelo estatal que, unindo a ética, a solidariedade e a responsabilidade intra e intergeracional, tem por fim edificar um mundo recheado de seres viventes dignos em todos os sentidos.

Dale Jamieson (2010, p. 27) nesse rumo, assevera que “[...] enquanto um único inocente morrer desnecessariamente por causa de danos ambientais causados por outros, haverá necessidade de reflexão ética".

No mais, só é possível pensar em um Estado Socioambiental de Direito se, de fato, os membros sociais agirem com coragem e de forma ética e, ademais, decidirem, com unhas e dentes, por proteger os bens naturais e tudo que o rodeiam para as presentes e futuras gerações. Nas palavras de André Trigueiro (2005, p. 80), “[...] sustentabilidade requer coragem, porque estamos falando de uma nova cultura política, de um novo modelo de gestão 
e de novos parâmetros para o desenvolvimento".

$\mathrm{Na}$ sequência, tratar-se-á, tendo por pano de fundo o Estado Socioambiental de Direito, acerca da construção de uma proposta de hermenêutica jurídica ambiental.

\section{A CONSTRUÇÃO DE UMA HERMENÊUTICA JURÍDICA AMBIENTAL COMO EXPRESSÃO DO ESTADO SOCIOAMBIENTAL DE DIREITO}

O presente artigo, como já explicitado, tem por fim apresentar argumentos doutrinários que abordem acerca da construção de uma hermenêutica jurídica ambiental, tendo por fim sua adequação com os pilares do Estado Socioambiental de Direito. Para tanto, indaga-se: há como se cogitar de métodos, técnicas e meios próprios de interpretação que, de fato, sirvam de base para uma firme edificação do Estado Socioambiental de Direito e, simultaneamente, auxiliem na solução dos conflitos sociais hodiernos?

Assim, a fim de dar azo à construção epistemológica, inicialmente tratar-se-á acerca da categoria Conhecimento numa visão puramente fenomenológica. ${ }^{18}$

O conhecimento, nas palavras de Johannes Hessen, é composto de três elementos, quais sejam: o sujeito, o objeto e a imagem. O sujeito é o determinado, aquele que apreende o objeto; o objeto é o determinante, aquele que é apreendido pelo sujeito ${ }^{19}$; a imagem, por sua vez, é a que nasce do objeto no sujeito em função de sua relação direta com o objeto ${ }^{20}$.

Assim, o conhecimento pode ser definido, segundo Johannes Hessen (1987, p. 27), "[...] como uma determinação do sujeito pelo objecto" ou seja, pode ser representado pela edificação de uma imagem nascida da relação direta do sujeito com o objeto.

Germana Parente Neiva Belchior (2011, p. 99), em sua obra Hermenêutica jurídica ambiental, também trata do tema, consignando que o conhecimento, no seu pensar, é "[...] formado por uma tríade: sujeito, atividade e objeto." O sujeito cognoscente é aquele ser dotado de razão, a atividade é elo de ligação entre o sujeito e objeto cognoscível e este é a peça fundamental e indispensável para a construção do conhecimento (BELCHIOR, 2011, p.

\footnotetext{
${ }^{18}$ Visão fenomenológica: “[...] aspira apreender a essência geral no fenómeno concreto.” In: HESSEN, Johannes. Teoria do conhecimento. Tradução de Antônio Correia. Coimbra: Editora Arménio Amado, 1987. Título original: Erkenntnistheórie. p. 26. Destaques no original.

19 “[...] A função do sujeito consiste em apreender o objecto, a do objecto em ser apreendido pelo sujeito." In: HESSEN, Johannes. Teoria do conhecimento. p. 26.

20 "“...] O objecto é determinante, o sujeito é o determinado. O conhecimento pode definir-se, por último, como uma determinação do sujeito pelo objecto. Mas o determinado não é o sujeito pura e simplesmente; mas apenas a imagem do objecto nele. Esta imagem é objectiva, na medida em que levam em si traços do objecto. Sendo distinta do objecto, encontrase de certo modo entre o sujeito e o objecto. Constitui o instrumento pelo qual a consciência cognoscente apreende o seu objecto.” In: HESSEN, Johannes. Teoria do conhecimento. p. 27.
} 
99-102).

Assim, a imagem só se solidifica na consciência quando, por meio de uma atividade e de uma escolha de caminho consciente, o sujeito cognoscente se debruça sobre o objeto determinado. Entretanto, de nada adianta gerar uma imagem sem que ela tenha uma correspondência verdadeira com o objeto, ou seja, tenha permitido edificar um conhecimento verdadeiro.

Johannes Hessen (1987, p. 29) aduz que "o conceito de verdade relaciona-se intimamente com a essência do conhecimento. Verdadeiro conhecimento é somente o conhecimento verdadeiro. Um <<conhecimento falso〉> não é propriamente conhecimento, mas sim erro e ilusão".

O conhecimento verdadeiro, como se assume, é o único que tem validade na teoria e na prática, pois é o que, de fato, permitirá formar uma imagem que traduza todos os elementos e traços do objeto determinado e, assim, não deturpará a transmissão de informações.

Fazendo uma analogia do exposto à hermenêutica jurídica, o sujeito cognoscente é o intérprete, o objeto cognoscível é o texto, a imagem é a norma e a verdade é traduzida pela a conexão entre o uso correto do meio e o resultado concretizado. Com base nestas categorias e conceitos que se abordará, a seguir, acerca da necessidade de se edificar uma consistente précompreensão geral e específica do intérprete.

A pré-compreensão, numa alusão à Hermenêutica Filosófica construída por HansGeorg Gadamer (1994), “[...] é constituída de uma estrutura prévia (Vorhabe), visão prévia (Vorsichti) e concepção prévia (Vorgriff), que já une todas as partes (textos) do 'sistema"” (STRECK, 2009, p. 304). De tal modo, a pré-compreensão é um processo que antecede o processo de interpretação e, por questões históricas e conceitos próprios do intérprete, permite significações distintas para um mesmo objeto.

Eros Roberto Grau (2009, p. 114), em sua obra Ensaio e discurso sobre a interpretação/aplicação do direito, versa sobre a teoria de Gadamer nos seguintes dizeres: "Compreender significa, primariamente, entender-se na coisa e apenas secundariamente destacar e compreender a opinião do outro como tal - a primeira de todas as condições hermenêuticas é a pré-compreensão que surge de ter que ver com o assunto mesmo".

Destarte, a pré-compreensão está baseada na história do ser intérprete, no seu legado, no seu conhecimento prévio, nos seus preconceitos, nos seus defeitos, nas suas virtudes, no trato com o poder, dentre outros caracteres que aproximam e afastam os seres em geral.

Neste contexto, Lênio Luiz Streck, tratando da teoria de Gadamer, pontua que o 
filósofo alemão foi um dos pioneiros a compor uma hermenêutica aliada a uma concepção filosófica, inclusive inovando e superando a hermenêutica baseada em métodos e técnicas (STRECK, 2009, p. 219). E mais: segundo o autor, Gadamer “[...] acentua que a interpretação da lei é uma tarefa criativa" (STRECK, 2009, p. 306), ou seja, que a interpretação não corresponde a um simples encaixe da norma ao caso concreto (uma simples reprodução), como acreditavam os hermeneutas metódicos, mas sim de uma resignificação contínua.

Lênio Luiz Streck advoga:

[...] Evidentemente, uma hermenêutica jurídica não pode contentar-se seriamente em empregar como padrão de interpretação o princípio subjetivo da ideia e intenção originárias do legislador. Em muitos casos, não pode evitar ter que aplicar conceitos objetivos, por exemplo, o da ideia jurídica que se expressa em uma lei. Aparentemente, é próprio de profanos imaginar a aplicação da lei a um caso concreto como processo lógico de submissão do particular para o geral (2009, p. 306).

É tão séria tal constatação que Eros Roberto Grau, em sua obra Direito Posto e o Direito Pressuposto, defende a ideia de que a norma, enquanto fruto da interpretação de um texto normativo, só tem validade quando estiver em consonância com o direito pressuposto, ou seja, com a realidade social contemporânea. ${ }^{21}$ Assim, o intérprete necessita exercer um processo produtivo e criativo com frequência para que o Direito, enquanto partícula dinâmica, permaneça vivo e responda, eficazmente, a todos os problemas sociais.

César Luiz Pasold, utilizando-se da expressão Percepção Jurídica, também defende a ideia de uma pré-compreensão como condição necessária para uma melhor captação da norma jurídica e, consequentemente, das bases teóricas do Direito. Assim conceitua a categoria em destaque: “[...] exame de norma jurídica (“legal; consuetudinária; jurisdicional; negocial”), descrevendo-a e emitindo juízo valorativo a respeito dela, com fundamento(s) em aporte(s) doutrinário(s) eleito(s)."22

Nas palavras do autor, em aulas ministradas da disciplina Fundamentos da Percepção Jurídica do Mestrado em Ciências Jurídicas da Univali, a percepção jurídica é sinônima de pré-hermenêutica jurídica, tendo por fim compor uma concepção prévia e sólida das bases do Direito e, assim, auxiliar no exame de valor das diversas espécies de norma jurídica. Aí já se concebe, como se constata, a necessidade de se construir uma pré-

\footnotetext{
21 “[...] podemos afirmar que a norma jurídica é legítima - dotada de legitimidade - quando existir correspondência entre o comando nela consubstanciado e o sentido admitido e consentido pelo todo social, a partir da realidade coletada como justificadora do preceito normatizado. A legitimidade é um conceito material, ao passo que a legalidade é um conceito formal." In: GRAU, Eros Roberto. O direito posto e o direito pressuposto. 8 ed. rev.amp. São Paulo: Malheiros, 2011. p. 86.

${ }^{22}$ Conceito disponibilizado pelo Prof. Dr. César Luiz Pasold aos alunos na disciplina "Fundamentos da Percepção Jurídica" do Mestrado em Ciências Jurídicas da Universidade do Vale do Itajaí - Univali em aulas ministradas no segundo semestre de 2015.
} 
hermenêutica jurídica que sirva, de fato, de alicerce para o processo interpretativo e, concomitantemente, conduza para a construção de um conhecimento jurídico verdadeiro e socialmente eficaz.

No campo do direito ambiental, Germana Parente Neiva Belchior, em sua dissertação fruto da realização do Mestrado em Ciências Jurídicas na Universidade Federal de Pernambuco, constrói um projeto de hermenêutica jurídica ambiental ${ }^{23}$ que coaduna com o exposto até momento. A autora defende a necessidade de construção de uma pré-compreensão ecológica geral a ser composta de uma “[...] ética ambiental antropocêntrica alargada e intergeracional, com base no princípio da responsabilidade, de uma educação ecológica e de uma racionalidade ambiental" (BELCHIOR, 2011, p. 124). Assim delineia:

[...] é preciso avaliar a forma da relação entre o homem e o meio ambiente e buscar uma convivência harmônica, para ser possível uma pré-compreensão ecológica apta para mudar os valores, pensamento, a atitude, modo como ocorre referida simbiose. Isso só pode ser possível com a superação da modernidade, haja vista que esta se caracteriza pelo logocentrismo e pelo igualitarismo antropocêntrico (2011, p. 116-117).

Inicialmente, a autora conduz seu relato reportando da necessidade de edificação de uma ética ambiental embasada numa visão antropológica alargada, qual seja, aquela que “[...] inclui a responsabilidade do homem para com a natureza e com a equidade geracional (solidariedade), e, ainda, a necessidade de valores e fundamentos éticos em relações aos outros seres" (BELCHIOR, 2011, p. 120). Como se verifica, há que se reconstruir uma ética ecológica, objetivando gerar uma pré-compreensão geral e, simultaneamente, dotar os seres humanos de meios para conviver eficientemente com o meio ambiente que os circunda.

$\mathrm{Na}$ sequência, versa acerca da conscientização ambiental como pilar para uma mudança do pensamento da sociedade de risco atual e edificação de uma sólida précompreensão ecológica. Assim aventa sobre a questão em comento:

Além da ética ambiental, outro fator que merece ser analisado para compor a pré-compreensão ambiental é a educação. Não há dúvida de que, quando mais se for educado, maior é a capacidade de lutar para exigir direitos e cumprir deveres. Isso é de suma importância para a efetivação do direito e do dever ao meio ambiente ecologicamente equilibrado, além dos diversos outros fatores que se interligam com a questão ambiental. A educação influencia a ética e vice-versa (BELCHIOR, 2011, p. 124).

A educação ambiental, destarte, é a base para a constituição de um pensamento distinto acerca da proteção eficiente do meio ambiente, bem como mola propulsora do Estado Socioambiental de Direito. Sem a presença de um ser vivente ecologicamente educado e de ações afirmativas que conduzam para a manutenção de nosso planeta, não há como se pensar

23 “[...] é mister uma hermenêutica jurídica ambiental que ofereça ao intérprete uma orientação dogmático-teórica e pragmática, objetivando efetivar o meio ambiente sábio por meio da captação de um sentido que seja conveniente com as metas e os postulados do Estado de Direito Ambiental." In: BELCHIOR, Germana Parente Neiva. Hermenêutica jurídica ambiental. p. 125. 
num Estado parcialmente interventor que tenha por base a solidariedade, a sustentabilidade e a concepção de uma eficaz justiça ambiental.

Ademais, a autora arremata o ponto em tela explicitando que "[...] um processo educacional em matéria ambiental proporcionará a reconstrução de valores, em especial, do valor sustentabilidade, marco teórico axiológico do Estado de Direito Ambiental" (BELCHIOR, 2011, p. 122).

Derradeiramente, a professora Germana consigna a racionalidade ambiental como último elemento estruturador da imperiosa pré-compreensão esverdeada geral. Conforme seus ensinamentos, resgatando os ensinamentos de Enrique Leff, “[...] a transformação do binômio homem-ambiente [...] só será possível mediante uma racionalidade ambiental, por meio de uma crítica à racionalidade da civilização moderna” (BELCHIOR, 2011, p. 123).

Sabiamente, Enrique Leff (2009, p. 18) pontua que “[...] a racionalidade ambiental abre caminho para uma reerotização do mundo, transgredindo a ordem estabelecida, a qual impõe a proibição de ser." E mais, nesse rumo, aponta que o saber ambiental, estruturante de uma racionalidade ambiental, "[...] muda o olhar do conhecimento e com isso transforma as condições do saber no mundo na relação que estabelece o ser com o pensar e o saber, com o conhecer e o atuar no mundo" (LEFF, 2009, p. 18).

É através de tal racionalidade ambiental, aliada a uma ética ambiental de visão antropocêntrica alargada e de uma educação de base ecológica que se compõe uma précompreensão esverdeada geral e, assim, permite-se estruturar uma visão holística do ser e consagrar os fins almejados pela sustentabilidade.

Em suma, tal pré-compreensão ambiental geral “[...] deve ser inerente a todas as pessoas, inclusive os intérpretes do Direito" (BELCHIOR, 2011, p. 124), ou seja, deve abarcar o ser vivente em sua essência, em seu âmago, em sua alma.

Ato contínuo, a professora Germana aborda acerca da necessidade adicional de se criar uma pré-compreensão específica do intérprete, sendo que, para tanto, destaca 10 hipóteses levantadas e defendidas ao longo de sua obra como premissas que, por sua essência, devem formar o imaginário do hermeneuta (BELCHIOR, 2011, p. 124-125).

Dentre os pontos enfatizados pela autora, registra-se o explanado nos pontos 9 e 10 :

9) o Estado de Direito Ambiental (que continua sendo um Estado Democrático de Direito) é um paradigma possível, com metas e objetivos a seres perseguidos. É construído por meio de um raciocínio jurídico dialético com predominância indutiva. Contém, ainda, um tripé axiológico fundamental: justiça (princípio da legitimidade), segurança jurídica (princípio da juridicidade) e sustentabilidade (princípio da solidariedade). 
10) os fundamentos hermenêuticos comprovam que o sentido é filosoficamente inesgotável. Dentro do Direito, que é um objeto cultural, o intérprete exerce um importante papel ao preencher a moldura deôntica criada pelo legislador influenciado pela sua pré-compreensão e pela realidade social (apofântico) no momento de sua aplicação (2011, p. 125).

No ponto 9, a autora apresenta os pilares axiológicos do Estado Socioambiental de Direito e advoga ser tal paradigma estatal meio possível a ser perseguido. No ponto 10, por sua vez, ela traduz a importância da hermenêutica filosófica na construção de tal modelo estatal, dando primazia à estrutura apofântica da norma em detrimento de sua base deôntica. ${ }^{24}$ Ambos os pontos, em conjunto com os demais listados pela autora, servem para formar uma pré-compreensão ambiental específica, como já exposto, e, assim, autorizar uma interpretação mais condizente com os ideais do Estado Socioambiental de Direito.

Resumidamente, tais pré-compreensões geral e específica, defendidas pela professora Germana em sua dissertação, tem por finalidade trabalhar uma pré-hermenêutica jurídica ambiental de caráter preventivo e epistemologicamente estruturador, bem como tem o escopo de formar a consciência ambiental do ser humano para gerir uma proteção eficiente de nosso planeta.

Do mesmo modo, José Joaquim Gomes Canotilho, preventivamente, aponta como uma proposta de pré-hermenêutica ambiental, embora assim não a trate, a construção de um remédio constitucional próprio, denominado Mandado de Injunção Ecológico, objetivando garantir, com primazia e em virtude do vácuo legislativo, a criação de textos normativos ambientais de proteção. Assim trata do tema:

A fórmula escolhida sugere a redescoberta do mandado de injunção consagrado na constituição Brasileira de 1988. Poderíamos recorrer a outros enunciados como "Habeas Naturale", "Acção de amparo ambiental", "Direito à normação ambiental". Do que se trata é de saber se quando as normas constitucionais, internacionais e legais, em matéria de ambiente, apresentarem inequívocos défices de exequibilidade, poderá reconhecer-se um qualquer direito à emanação de normas concretizadoras (2001, p. 13).

Enaltecendo o aspecto transnacional do Estado Constitucional Ecológico, o autor português defende, nesse viés, que, na ausência de regra regulamentadora ou em caso de inequívocos déficits de prestação estatal, o mandado de injunção ecológico, remédio próprio a ser criado para o fim de proteção ambiental, tem por fito criar a regra interna ou, quiçá, atingir a seara normativa internacional. Seria um instrumento, portanto, não apenas para amparar o direito interno, mas também defender uma regulamentação de âmbito global.

\footnotetext{
24 “[...] o apofântico é que permite a justiça e a equidade das decisões judiciais, por meio do movimento indutivo. Assim, quando a norma é criada pelo legislador, permanece no campo deôntico, do dever-ser, formando uma espécie de moldura, que não poderá nunca ser engessada, como queria o positivismo jurídico. Caberá ao intérprete o preenchimento dessa moldura, com a captação de um (ou vários) sentido(s) guiado(s) por meio da hermenêutica jurídica. Sentido este, obviamente, que deverá acompanhar os reclamos da sociedade.” In: BELCHIOR, Germana Parente Neiva. Hermenêutica jurídica ambiental. p. 115 .
} 
Num trabalho interpretativo repressivo, aqui sendo tratado como aquele que sai da esfera de formação pessoal do intérprete e se aventura para servir como instrumento para a edificação da norma partindo do texto normativo já erguido, Germana Parente Neiva Belchior erige uma proposta de hermenêutica jurídica ambiental baseada em “[...] princípios de interpretação que objetivam a busca de soluções justas e constitucionalmente adequadas para a interpretação de normas ambientais, influenciados pela nova pré-compreensão ambiental" (BELCHIOR, 2011, p. 128).

Por oportuno, a autora utiliza-se de princípios fundantes (BELCHIOR, 2011, p. 129130) (princípio da legitimidade, princípio da juridicidade e princípio da solidariedade), princípios estruturantes (BELCHIOR, 2011, p. 130-151) (princípio da precaução, princípio da prevenção, princípios da responsabilização e do poluidor-pagador princípios da democracia, da cidadania, da informação da educação e da participação ambiental, princípio da proibição do retrocesso ecológico e princípio do mínimo existencial ecológico) e princípios de interpretação constitucional (BELCHIOR, 2011, p. 151-158) (princípio da razoabilidade, o princípio da ponderação e princípio da proporcionalidade).

Versando de cada princípio, a autora aponta seu conceito e sua forma de aplicação, bem como constrói uma hermenêutica jurídica ambiental que possibilita edificar uma norma de viés fortemente protetivo e altamente condizente com os pilares do Estado Socioambiental de Direito.

Nesse fervor interpretativo repressivo, Thiago Cássio D’Ávila Araújo pontua que, na insurgência de um conflito aparente de normas, há que se edificar um critério ambiental, qual seja, um critério que permita aplicar a norma que não agrida o meio ambiente, ou no caso de agressão, que menos proporcione malefícios (ARAÚJO, 2007, p. 167-177). Assinala o autor:

É preciso que na estrutura do Estado Ambiental de Direito exista uma Teoria do Ordenamento Jurídico Ambiental, de maneira que, aos critérios propostos por Bobbio, acrescente-se o critério ambiental. Portanto, existe uma nova forma de se encarar o ordenamento jurídico: sob o critério ambiental. E nisso o Direito Ambiental inaugura uma nova dimensão espacial no espaço jurídico, inserem-se as normas ambientais com caráter de coordenação do direito positivo (ARAÚJO, 2007, p. 167-177).

Seja num caráter preventivo ou numa concepção interpretativa repressiva, a construção de uma hermenêutica jurídica ambiental, ante a edificação paulatina de um Estado Socioambiental de Direito, necessita compreender uma visão ontológica da sustentabilidade, ou seja, carece buscar a essência, o elixir, a origem do termo conjugando-o com suas dimensões (ambiental, social, econômica, ética, dentre outras defendidas pela doutrina).

Assim, somente por meio desta visão ontológica da sustentabilidade que será 
possível construir, efetivamente, os pilares do Estado Socioambiental de Direito e, consequentemente, fazer valer o papel do ser vivente de protetor contumaz de nossa mãe Gaia.

\section{CONSIDERAÇÕES FINAIS}

O presente trabalho buscou identificar possíveis métodos, técnicas e meios próprios de interpretação que traduzam os anseios do Estado Socioambiental de Direito e, simultaneamente, auxiliem na solução dos atuais conflitos sociais.

Observou-se que o Estado Socioambiental, além de manter os direitos já conquistados pelos modelos anteriores, é profundamente regido por princípios ecológicos de caráter holístico, integral e sistemático, tendo por fim buscar a qualidade das vidas humanas e não humanas, valendo-se, para tanto, da dignidade de todos os seres viventes.

Assim, restou confirmada a hipótese inicialmente levantada: diante do Estado Socioambiental de Direito e sua base solidária, há que se edificar uma proposta hermenêutica que traduza os anseios do paradigma estatal em formação, bem como que seja capaz de solucionar os conflitos sociais atuais. A construção de tal hermenêutica, assim como a construção do Estado Socioambiental de Direito, deve ser balizada pela visão ontológica da sustentabilidade, considerando todas as suas dimensões, bem como pela formação sólida de uma pré-compreensão geral e específica do intérprete, o que, em nosso entender, deve ser institucionalizada e concretizada o mais rápido possível.

\section{REFERÊNCIAS DAS FONTES CITADAS}

ARAÚJO, Thiago Cássio D'Ávila. Estado Ambiental de Direito. Revista da AGU, v. 6, p. 167-177, 2007.

ARMADA, Charles Alexandre Souza. O estado socioambiental de direito brasileiro e a concretização multidimensional da sustentabilidade. Revista Eletrônica Direito e Política, Programa de Pós-Graduação Stricto Sensu em Ciência Jurídica da UNIVALI, Itajaí, v.10, n.1, edição especial de 2015; p. 157-174.

BECK. Ulrich. Sociedade de Risco. Rumo a Outra Modernidade. 2 ed. São Paulo: Editora 34, 2011.

BELCHIOR, Germana Parente Neiva. Hermenêutica jurídica ambiental. São Paulo: Saraiva, 2011.

BOBBIO, Norberto. A Era dos Direitos. Rio de Janeiro: Campus, 1992. 
BODIN. Jean. Os Seis Livros da República. Tradução de José Ignácio Coelho Mendes. São Paulo: Saraiva. Título Original: Les six livres de la République (1576).

BODNAR, Zenildo; ROSSETTO, Adriana Marques; BODNAR, Roberta Terezinha Uvo. A avaliação ambiental estratégica no planejamento das cidades. In: SOUZA, Maria Claudia da Silva Antunes de. (coord.) Avaliação Ambiental Estratégica: possibilidades e limites como instrumento de planejamento e apoio à sustentabilidade. Belo Horizonte: Arraes Editores, 2015.

BOFF, Leonardo. Sustentabilidade: o que é, o que não é. 3. ed. Petrópolis: Editora Vozes, 2014.

BONAVIDES, Paulo. Teoria Constitucional da Democracia Participativa. Por um Direito Constitucional de luta e resistência. Por uma Nova Hermenêutica. Por uma repolitização da legitimidade. 1 ed. São Paulo: Malheiros, 2001.

Teoria Geral do Estado. 8 ed. São Paulo: Malheiros Editores. 2010.

BOSSUET. Jacques. Política Tirada das Santas Escrituras (1708). Título Original: Politique Tirée des propres paroles de L'ecreiture Sainte.

BRASIL. Constituição da República dos Estados Unidos do Brasil de 16 de julho de 1934. Disponível em: < http://www.planalto.gov.br/ccivil_03/Constituicao/Constituicao34.htm> Acesso em: 26 de jun de 2016 Destaque nosso.

. Constituição da República Federativa do Brasil de 1988. Disponível em: <http://www.planalto.gov.br/ccivil_03/constituicao/ConstituicaoCompilado.htm> Acesso em: 26 de jun 2016. Destaque nosso.

Lei n. 8.078, de 11 de setembro de 1990. Dispõe sobre a proteção do consumidor e dá outras providências. Disponível em: https://www.planalto.gov.br/ccivil_03/LEIS/L8078.htm>. Acesso em 13/07/2016.

CANOTILHO. José Joaquim Gomes; MOREIRA, Vital. Fundamentos da Constituição. Coimbra: Coimbra, 1991.

CANOTILHO, José Joaquim Gomes. Estado constitucional e democracia sustentada. RevCEDOUA. Vol. 4, No 8, 2001.

CAPRA, Fritjof. Teia da vida. Tradução de Newton Roberval Eichemberg. São Paulo: Editora Cultrix, 2006. Título original: The Web of Life - A New Scientific Understanding of Living Systems.

CRUZ. Paulo Márcio. Política, Poder, Ideologia e Estado Contemporâneo. 3 ed. rev. ampl. e atual. Curitiba: Juruá, 2003. 
Da soberania à Transnacionalidade: democracia, direito e estado no século XXI. Itajaí: Editora Univali, 2011.

Declaração Universal dos Direitos Humanos: adotada e proclamada pela resolução 217 A (III) da Assembléia Geral das Nações Unidas em 10 de dezembro de 1948. Disponível em $<$ http://unesdoc.unesco.org/images/0013/001394/139423por.pdf> Acesso em: 26 de jun de 2016.

FENSTERSEIFER, Tiago. Direitos fundamentais e proteção do ambiente: a dimensão ecológica da dignidade humana no marco jurídico constitucional do Estado Socioambiental de Direito. Porto Alegre: Livraria do Advogado Editora, 2008.

FERREIRA, Maria Leonor Paes Cavalcanti; LEITE, José Rubens Morato. Estado de Direito Ambiental: $O$ antropocentrismo alargado e o direito da fauna. Mitteilungen der Deutsch Brasilianischen Juristenvereinigung, Internet, p. 27-39, 2004.

GADAMER, Hans-Georg. Verdad y Método I. Salamanca: Ediciones Sígueme. 1994.

. Verdad y Método II. Salamanca: Ediciones Sígueme. 1994.

GRAU, Eros Roberto. Ensaio e discurso sobre a interpretação/aplicação do direito. 5 ed. revista e ampliada. São Paulo: Malheiros, 2009.

GRAU, Eros Roberto. O direito posto e o direito pressuposto. 8 ed. rev.amp. São Paulo: Malheiros, 2011.

HERNÁNDEZ, Javier Gonzaga Valencia. Estado ambiental, democracia y participación ciudadana en Colombia a partir de la constitución de 1991. Revista Jurídicas (Manizales Colombia), v. 4(2), p. 163-185, 2007.

HESSEN, Johannes. Teoria do conhecimento. Tradução de Antônio Correia. Coimbra: Editora Arménio Amado, 1987. Título original: Erkenntnistheórie.

HOBBES, Thomas. Leviatã ou Matéria, Forma e Poder de um Estado Eclesiático e Civil. Tradução de Alex Martins. São Paulo: Editora Martin Claret. Título original: Leviathan, ou Matter, Form and Power of a Commenweath Ecclesiastical and Civil. 2002.

JAMIESON, Dale. Ética e meio ambiente: uma introdução. Tradução de André Luiz de Alvarenga. São Paulo: Editora Senac São Paulo, 2010. Título original: Ethics and the environment: an introduction.

KANT, Immanuel. Fundamentação da metafísica dos costumes. Tradução de Paulo Quintela. Coimbra: Instituto de Alta Cultura, 1960. Título original: Grundlengung zur Metaphysik der Sitten.

LEFF, Enrique. Complexidade, racionalidade ambiental e diálogo dos saberes. Educação e Realidade, v. 34(3), p. 17-24, set/dez 2009. 
LEITE, José Rubens Morato; AYALA, Patryck de Araújo. Direito ambiental na sociedade de risco. $2^{a}$ ed. revista, atualizada e ampliada. Rio de Janeiro: Forense Universitária, 2004.

MAQUIAVEL, Nicolau (Niccolò di Bernardo dei Machiavelli). O Príncipe. Tradução de Pietro Nassetti. São Paulo: Editora Martin Claret. Título original: il Principe. 2007.

MARIN, Jeferson Dytz; LEONARDELLI, P. P. O Estado Socioambiental: a afirmação de um novo modelo de Estado de Direito. Revista Direitos Fundamentais \& Democracia (UniBrasil), v. 14, 2013 p. 374-386.

MENDES. Gilmar Ferreira; BRANCO. Paulo Gustavo Gonet. Curso de Direito Constitucional. 8 ed. rev. e atual. São Paulo: Saraiva, 2013.

PASOLD, Cesar Luiz. Metodologia da Pesquisa Jurídica: Teoria e Prática. 13 ed. rev. atual. amp. Florianópolis: Conceito Editorial, 2015.

SILVA. José Afonso da. Curso de Direito Constitucional Positivo. 24 ed. São Paulo: Malheiros. 2005.

SPAREMBERGER, R. F. L.; FERRONATTO, Rafael Luiz. ; Petry, Diogo ; FORTES, Vinicius M. O Estado constitucional ecológico e o Estado socioambiental de direito como formas de assegurar o meio ambiente ecologicamente equilibrado. Diritto \& Diritti, v. 28, p. 01-22, 2009.

STRECK, Lênio Luiz. Hermenêutica jurídica e(m) crise: uma exploração hermenêutica da construção do direito. 8 ed. ver. atual. Porto Alegre: Livraria do Advogado Editora, 2009.

TRIGUEIRO, André. Mundo sustentável. São Paulo: Globo, 2005. 